\title{
Wear and abrasivity: observations from EPB drives in mixed soft - rock sections
}

This paper summarizes the main observations related to geotechnical properties and tool changes that characterize the different tunnel drives in a database of $33 \mathrm{~km}$ of EPB tunnel records from the Barcelona area. The data have been examined in detail with regard to cutting tool replacement and performance of the mechanized excavation. The database includes tunnels in soft soils, in hard and medium rocks and in mixed soil-rock conditions; tool changing records and geotechnical properties. Transverse and longitudinal geotechnical heterogeneity are accounted for systematically. Longitudinal heterogeneity is used to subdivide the drives in the database into homogeneous units. Transverse (within section) heterogeneity is described by a set of newly developed impact factors $\mathrm{Fl}$.

\section{Introduction}

The Barcelona hinterland is quite varied from the geotechnical viewpoint, comprising material ranging from granite to soft clay. The Linea 9 and Terrassa FGC projects are large recent extensions of the Metro network [1]. The database is comprised of eleven tunnel drives (UP) that were part of the projects. The UP characteristics are described in Table 1. This data is analyzed in more detail, subdividing each drive into various stretches. These were defined in two different ways: one derived from the nature of the ground excavated; another using the records of stops for cutterhead repair and tool change. This article summarizes the main observed characteristics of the tunnel stretches defined in this way. More details can be found in [1], [2].

\section{Geotechnical stretches (TG)}

A characteristic of the database under study was noticeable material heterogeneity in both the longitudinal and transverse section. Quantifying this factor was deemed
Table 1. Tunnel drives: main characteristics

\begin{tabular}{l|l|l|l}
\hline Drive & Contract name & Length $[\mathbf{m}]$ & Diameter [m] \\
\hline UP1 & IV A Can Zam & 4293 & 11.95 \\
\hline UP2 & IV B Gorg & 4000 & 11.95 \\
\hline UP3 & IV C Trajana & 645 & 11.95 \\
\hline UP4 & IV C Doble tunel & 1300 & 11.95 \\
\hline UP5 & IV D Doble tunel & 1508 & 11.95 \\
\hline UP6 & II Bif.-Z. Univ. & 3310 & 11.95 \\
\hline UP7 & IA Eixample N-Airport & 4328 & 9.4 \\
\hline UP8 & IB Fira II-Parc Logistic & 1065 & 9.4 \\
\hline UP9 & IC Eixam. N-Parc Log & 6687 & 9.4 \\
\hline EI & Egara I & 3147 & 6.9 \\
\hline EII & Egara II & 3132 & 6.9 \\
\hline
\end{tabular}

necessary because there are indications that mixed face heterogeneity might affect tool wear [1], [3], [5]. Mixed faces were composed of soils, soft and hard rock, as shown schematicaly in the next diagram (Fig. 1).

A geotechnical stretch TG is defined as one in which materials at the mixed face maintain an approximately constant proportion of areas and spatial disposition. Section changes were established by examining the "as built" longitudinal geotechnical sections of each drive. More about the criteria adopted to define the limit point can be seen in [1].

\subsection{Longitudinal heterogeneity}

Ground changes along the drive define longitudinal heterogeneity. In total 143 TG were determined in the L9 UPs

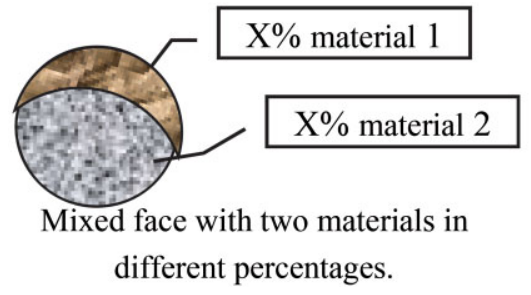

Fig. 1 Different cases of mixed faces

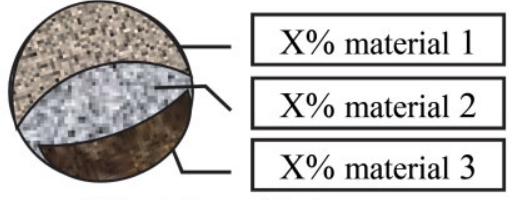

Mixed face with three materials in different percentages.

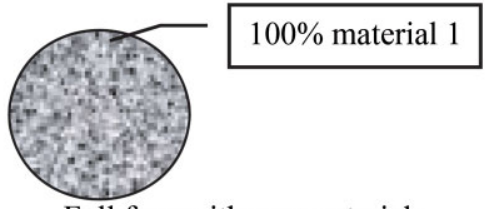

Full face with one material; homogeneous section 


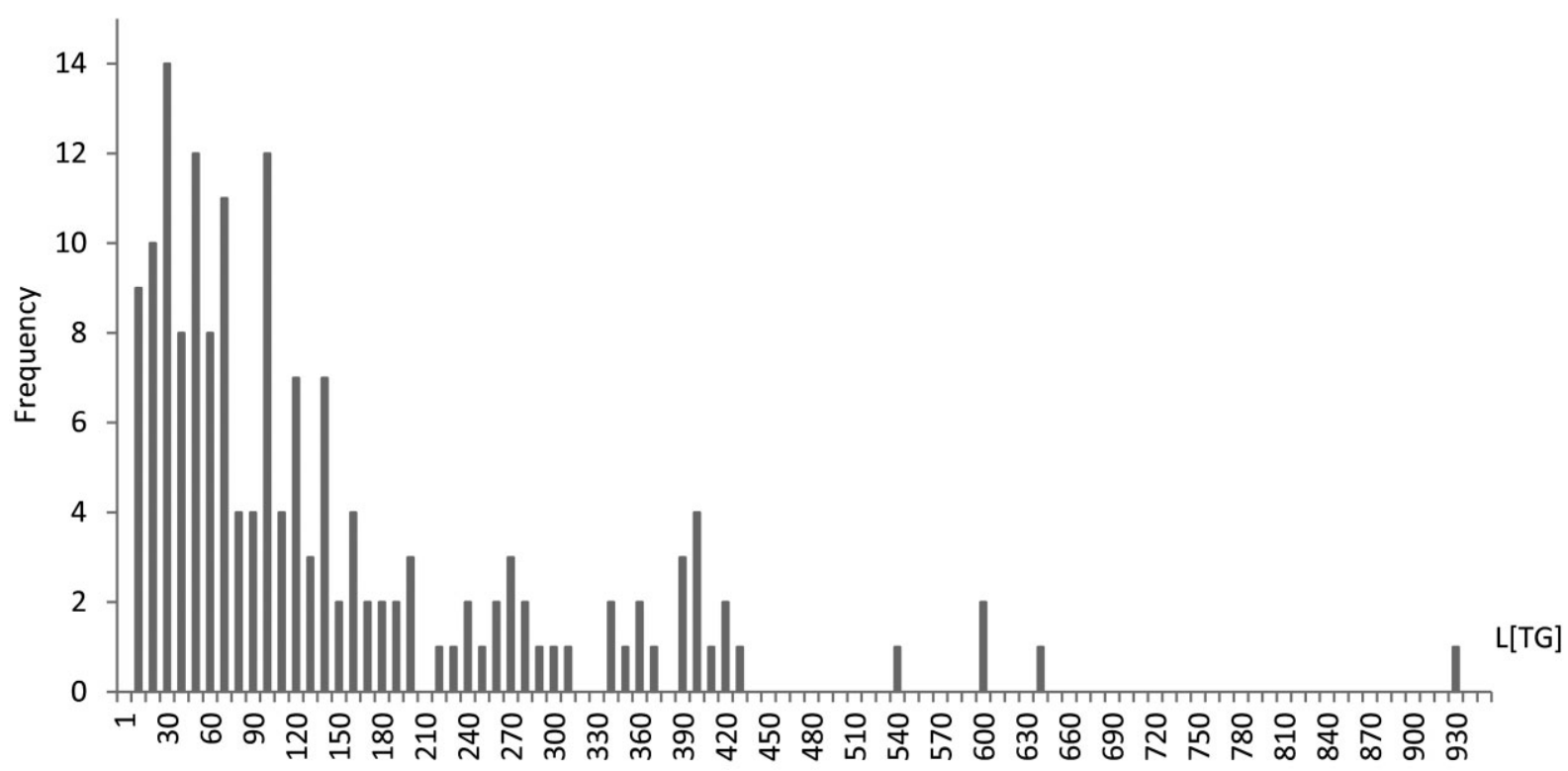

Fig. 2. L[TG] Histogram

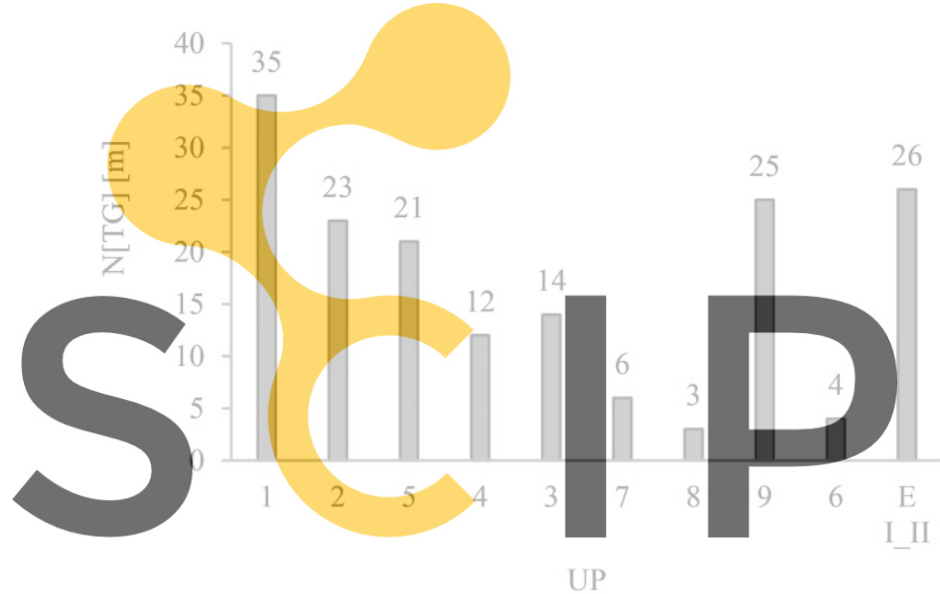

Regisiger. forr free ratt dittoststwww.scipedia.com to

and 26 in the Terrassa UPs. For the L9 project, the average length $\bar{L}[\mathrm{TG}]$ is $190 \mathrm{~m}$ with a minimum value of $3 \mathrm{~m}$ and a maximum of 2,550 $\mathrm{m}$. This variable is very varied, as indicated by a ratio of standard deviation to mean (coefficient of variation, $\mathrm{CV}$ ) of 1.65 . In the Terrassa Project, the values are less varied. In L9, the most frequent $L[T G]$ value is $30 \mathrm{~m}$ whereas that in Terrassa is $140 \mathrm{~m}$. Fig. 2 shows the histogram of L[TG] from both L9 and Terrassa. The number of TG (N[TG]) grouped for drive (UP) is represented in a bar chart (Fig. 3). In Table 2 this value, L[UP] and more statistics are shown, broken down by UP.

The bar chart in Fig. 3 shows that some drives were more heterogeneous than others, denoted by a higher figure for TG, e.g. UP1, UP9 or EI/II. In Fig. 4, L[TG] are shown against CVL[TG] values in each UP. From these results it follows that

- In L9 the most heterogeneous drive was UP1, in which each stretch represented less than $3 \%$ of the drive on average. By contrast, the most homogeneous drive was UP6, where only four different geotechnical scenarios were found in a total of $3,310 \mathrm{~m}$.

- The UP longitudinal heterogeneity, understood as jumps between very long and very short stretches, is expressed

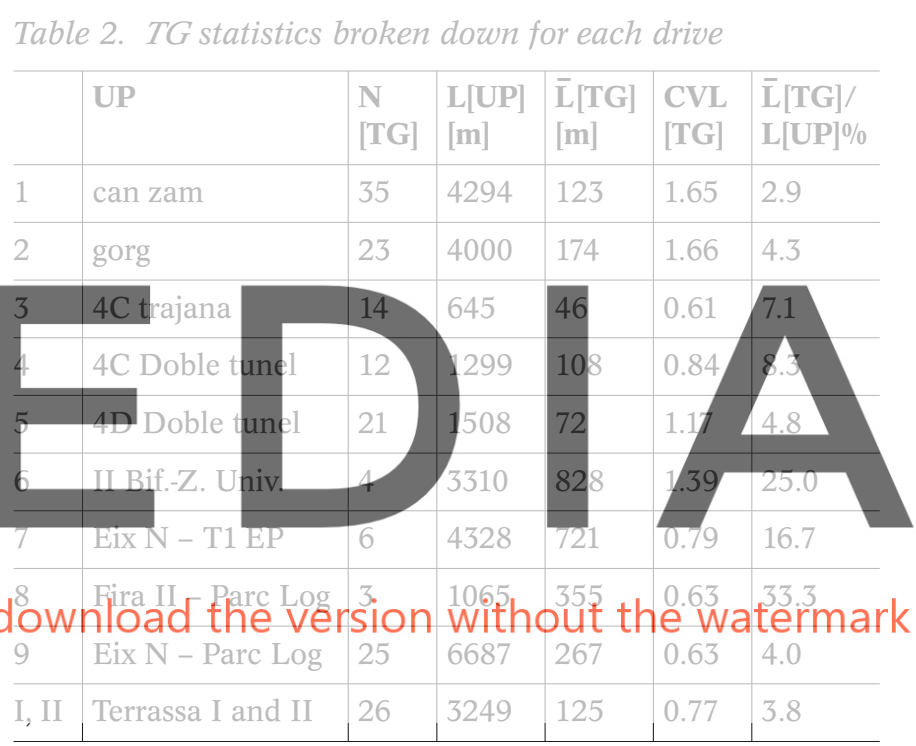

by the coefficient of variation of L[UP]. This is higher in UP1 and UP2 and lower in UP3. High variability indicates the presence of very short stretches such as igneous dikes or fault zones.

- Drives UP4 and UP5 were almost parallel but showed significant geotechnical differences. UP5 has higher CVL[TG] values, denoting greater heterogeneity than UP4.

- UP9 is the longer drive, although it is more homogeneous than others that are far shorter. It is clearly shown that UP length and longitudinal heterogeneity are two different parameters.

\subsection{Transverse heterogeneity}

Up to three materials were detected in the same section. From a total of 169 TG, 63 contained only one material (homogeneous sections), a total of 13,449 m. 73 TG had mixed sections with two materials, a total of $13,640 \mathrm{~m}$. Finally, 33 TG had mixed sections with three materials, 


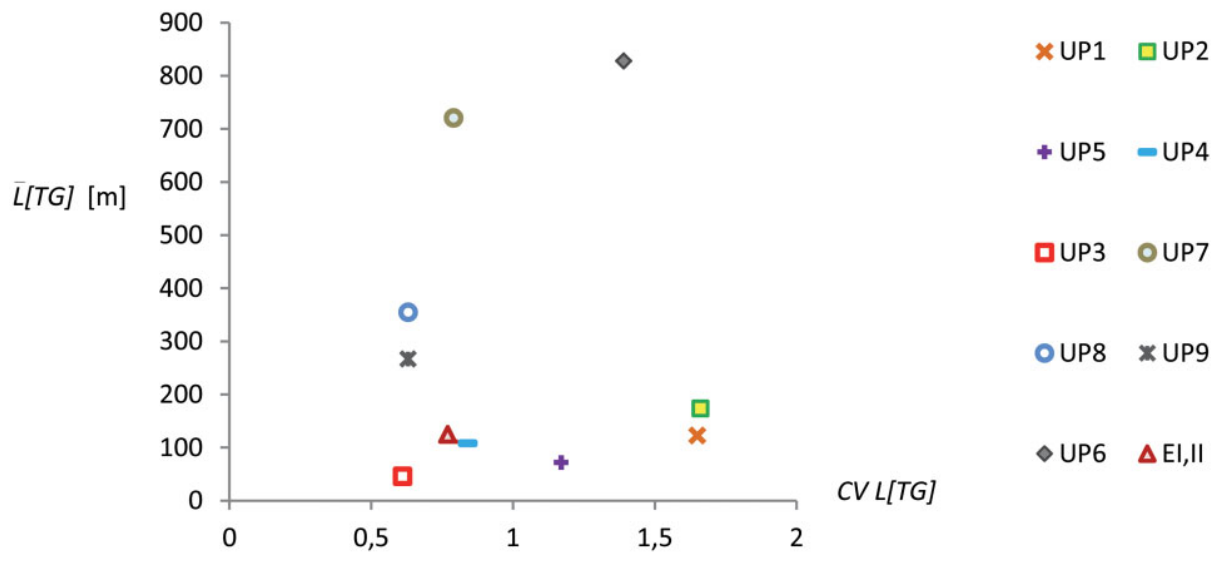

Fig. 4. $\bar{L}[T G]$ against $C V L[T G]$ in each $U P$

adding to 3,329 $\mathrm{m}$. The number of stretches and their average length $\overline{\mathrm{L}}[\mathrm{TG}]$ in each transverse section category and project are shown in Table 3 . Table 4 presents the same type of data, but now broken down for each drive $(U P)$.

Regarding the number of occurrences of each kind of transverse section (N[TG1], N[TG2], N[TG3]), their aggregated length L[TGi] and perceptual relationship between these aggregated lengths and total UP length, it appears that the number and length of TGs with one or two materials are similar whereas TGs with three materials on the
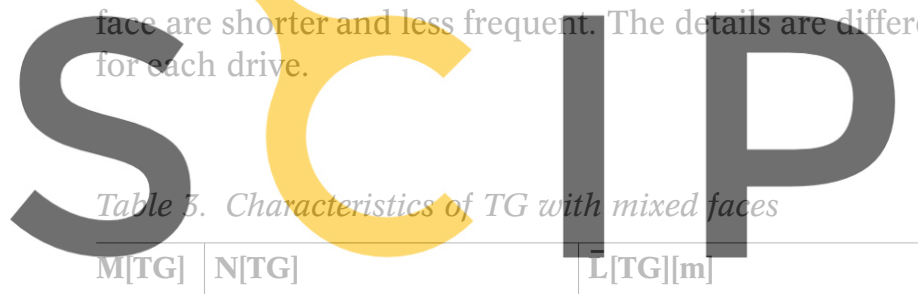

IM[TG] N[TG

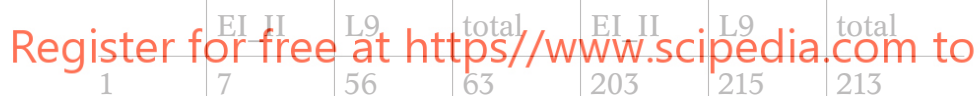

\begin{tabular}{l|l|l|l|l|l|l}
\hline 1 & 7 & 56 & 63 & 203 & 215 & 213 \\
\hline 2 & 11 & 62 & 73 & 79 & 206 & 187 \\
\hline 3 & 8 & 25 & 33 & 120 & 95 & 101 \\
\hline
\end{tabular}

\subsection{Geotechnical properties on a TG stretch: definitions}

After a geotechnical stretch (TG) was defined, equivalent geotechnical properties were assigned to it based on the properties of the different materials appearing in the section. Thus an equivalent abrasivity and strength of the mixed face were calculated as the area-weighted average of face material properties. Thus,

\section{Abreq $\left[\mathrm{TG}_{\mathrm{i}}\right]=\sum^{\mathrm{m}} \mathrm{Abr}[\mathrm{UG}]_{\mathrm{j}} \mathrm{P}_{\mathrm{ij}}$}
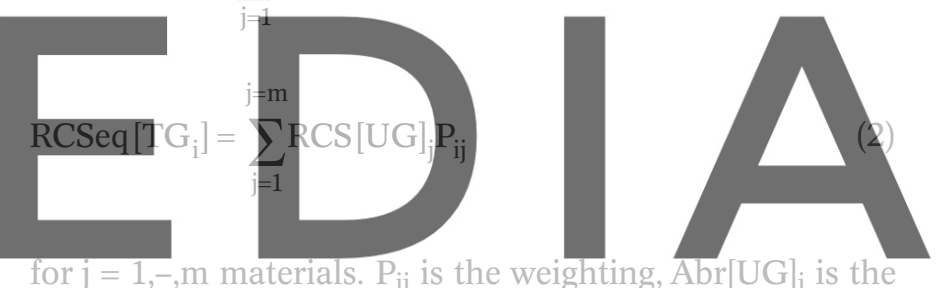

LCPC abrasivity value ( $\mathrm{g} / \mathrm{t}$ ) determined for each material

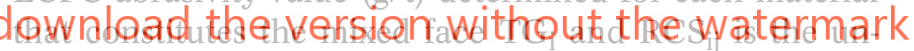
confined compression strength of each material $j$ appearing in the face characterizing stretch i. Further discussion about the LCPC test results for Barcelona materials can be found in [1], [4].

Table 4. UP broken down figures of transverse heterogeneous TG

\begin{tabular}{|c|c|c|c|c|c|c|c|c|c|c|}
\hline \multirow[t]{2}{*}{$\mathbf{U P}$} & \multirow[t]{2}{*}{ NTG/UP } & \multicolumn{4}{|c|}{$\mathbf{M}[\mathbf{T G}]=\mathbf{1}$} & \multicolumn{3}{|c|}{$\mathbf{M}[\mathbf{T G}]=2$} & \multicolumn{2}{|c|}{$\mathbf{M}[\mathbf{T G}]=3$} \\
\hline & & NTG1 & $\begin{array}{l}\text { L[TG1] } \\
{[\mathrm{m}]}\end{array}$ & $\begin{array}{l}\text { L[TG1]/ } \\
\text { UP [\%] }\end{array}$ & NTG2 & $\begin{array}{l}\text { L[TG2] } \\
{[\mathrm{m}]}\end{array}$ & $\begin{array}{l}\text { L[TG2]/ } \\
\text { UP [\%] }\end{array}$ & NTG3 & $\begin{array}{l}\text { L[TG3] } \\
{[\mathrm{m}]}\end{array}$ & $\begin{array}{l}\text { L[TG3]/ } \\
\text { UP [\%] }\end{array}$ \\
\hline 1 & 35 & 29 & 3827 & $89 \%$ & 6 & 466 & $11 \%$ & & & \\
\hline 2 & 23 & 3 & 1573 & $39 \%$ & 11 & 1566 & $39 \%$ & 9 & 865 & $22 \%$ \\
\hline 3 & 14 & 2 & 120 & $19 \%$ & 4 & 195 & $30 \%$ & 8 & 330 & $51 \%$ \\
\hline 4 & 12 & 4 & 689 & $53 \%$ & 5 & 340 & $26 \%$ & 3 & 270 & $21 \%$ \\
\hline 5 & 21 & 4 & 161 & $11 \%$ & 15 & 1012 & $67 \%$ & 2 & 335 & $22 \%$ \\
\hline 6 & 4 & 4 & 3310 & $100 \%$ & & & - & & & - \\
\hline 7 & 6 & 0 & & - & 6 & 4328 & $100 \%$ & & & \\
\hline 8 & 3 & 2 & 645 & $61 \%$ & 1 & 420 & $39 \%$ & & & \\
\hline 9 & 25 & 8 & 1702 & $25 \%$ & 14 & 4445 & $66 \%$ & 3 & 540 & $8 \%$ \\
\hline $\mathrm{E} \mathrm{I} / \mathrm{II}$ & 26 & 7 & 1422 & $44 \%$ & 11 & 868 & $27 \%$ & 8 & 959 & $30 \%$ \\
\hline
\end{tabular}


The transverse geotechnical heterogeneity in a mixed face could have an important effect on wear and, in gener$\mathrm{al}$, on damage to cutter tools. More contrast in the geotechnical property values will lead to more jumping of the cutter tool and the impact will be more damaging. An impact factor (FI) was defined to quantify this from the geotechnical property values of different materials present in those faces.

Suppose there are two materials in the section, whose properties are $\left(\mathrm{x}_{1} ; \mathrm{x}_{2}\right)$, assuming $\left(\mathrm{x}_{1} \geq \mathrm{x}_{2}\right)$. An impact factor for this two-material case is defined based on their ratio $\mathrm{r}=\mathrm{x}_{1} / \mathrm{x}_{2}$ as:

$\mathrm{FI}=\mathrm{f}_{2}(\mathrm{r})=\frac{1+\mathrm{r}}{2 \sqrt{\mathrm{r}}}$

This expression simply results from the ratio between the arithmetic and geometric average of values $\left(\mathrm{x}_{1} ; \mathrm{x}_{2}\right)$. This is:

$$
f_{2}\left(x_{1}, x_{2}\right)=\frac{\left(x_{1}+x_{2}\right)}{2 \sqrt{x_{1} x_{2}}}
$$

In the case with three different materials, two property ratios $\left(\mathrm{r}_{1} ; \mathrm{r}_{2}\right)$ are calculated, assuming $\left(\mathrm{x}_{1} \geq \mathrm{x}_{2} \geq \mathrm{x}_{3}\right)$

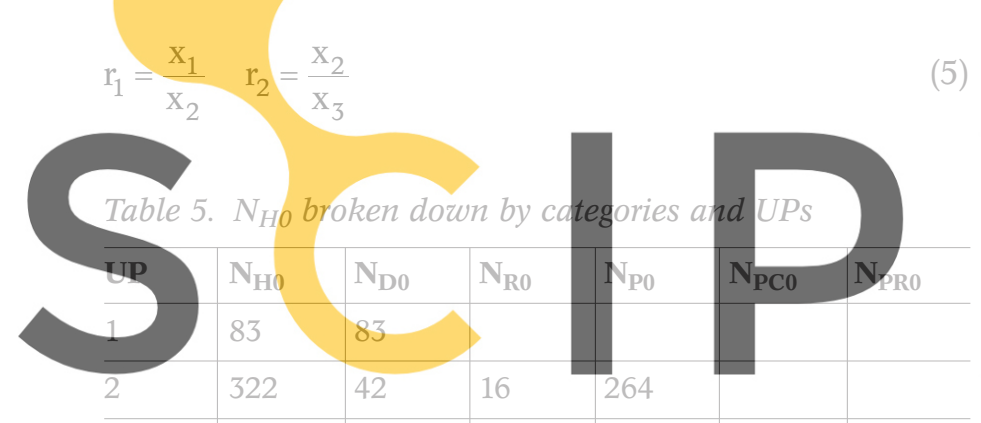

Register for ${ }^{352}$ free ${ }^{66}$ at https//www.scipedia.com to

\begin{tabular}{l|l|l|l|l|l|l}
\hline 4 & 358 & 72 & 48 & 238 & & \\
\hline 5 & 322 & 42 & 16 & 264 & & \\
\hline 6 & 322 & 42 & 16 & 264 & & \\
\hline 7 & 322 & 42 & 16 & 264 & & \\
\hline 8 & 322 & 42 & 16 & 264 & & \\
\hline 9 & 322 & 42 & 16 & 264 & & \\
\hline EI & 160 & & & & 56 & 104 \\
\hline EII & 160 & & & & 56 & 104
\end{tabular}

The proposed impact factor expression for the three-material case is:

$\mathrm{FI}=\mathrm{f}_{3}\left(\mathrm{r}_{1}, \mathrm{r}_{2}\right)=\sqrt{\left(\frac{1+\mathrm{r}_{1}}{2 \sqrt{\mathrm{r}_{1}}}\right)\left(\frac{1+\mathrm{r}_{2}}{2 \sqrt{\mathrm{r}_{2}}}\right)}$

A detailed discussion of these definitions can be found in [1]. Impact factors thus defined can be computed for any material property, which is deemed relevant and for which there are data for all materials in the section. In this case, the two properties selected were unconfined compressive strength (RCS) and LCPC abrasivity (Abr). The values thus computed constitute two new properties of each geotechnical FI_RCS[TGi] as FI_Abr Abr[TGi].

\section{Maintenance stretches (TRDC)}

Each drive was again divided according to cutterhead maintenance data. Each segment thus obtained is a cutterhead maintenance stretch (briefly, TRDC). A TRDC covers the space between two stops where tool replacement was recorded; stoppages for other reasons than tool replacement are excluded. The TBMs under study were EPB type, generally equipped with discs, picks and scrapers. The machine for drive UP1 was different: it could operate either in open or closed mode and only had discs. Table 5 presents the number of tools of each category mounted on

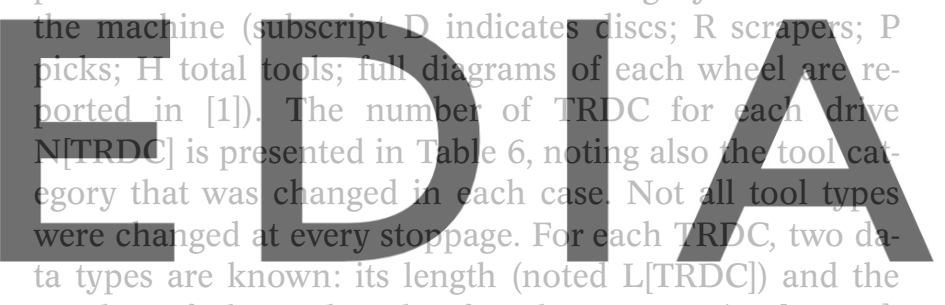
number of changed tools of each category $\left(N_{D}\right.$ [TRDC]

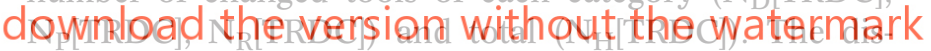

Table 7. L[TRDC] statistics

\begin{tabular}{l|l|l}
\hline & L9 & Terrassa \\
\hline Media $(\mathrm{m})$ & 126 & 293 \\
\hline S.Desv. & 283 & 177 \\
\hline Max.-Min. & 2337 & 670 \\
\hline CV & 2.25 & 0.6 \\
\hline
\end{tabular}

Table 6. N[TRDC] broken down by categories and UPS

\begin{tabular}{l|l|l|l|l|l|l|l|l|l|l|l|l}
\hline & UP1 & UP2 & UP3 & UP4 & UP5 & UP6 & UP7 & UP8 & UP9 & EI & EII & Total UP \\
\hline D & 122 & 7 & 3 & 8 & 11 & 14 & 5 & 3 & 3 & - & - & 176 \\
\hline P & - & 12 & 3 & 14 & 11 & 10 & 5 & 4 & 6 & - & - & 65 \\
\hline R & - & 8 & 3 & 10 & 2 & - & 4 & 3 & 5 & - & - & 35 \\
\hline PC & - & - & - & - & - & - & - & - & - & 6 & 7 & 13 \\
\hline PR & - & - & - & - & - & - & - & - & - & 3 & 2 & 5 \\
\hline H & 122 & 13 & 3 & 15 & 14 & 18 & 5 & 5 & 6 & 7 & 7 & 215 \\
\hline
\end{tabular}


Table 8. L[TRDC-X] broken down by categories

\begin{tabular}{l|l|l|l|l|l}
\hline & L[TRDC-D] & L[TRDC-P] & L[TRDC-R] & L[TRDC-PC] & L[TRDC-PR] \\
\hline Media & 142.8 & 311.5 & 492.2 & 295 & 365 \\
\hline S.Desv. & 352.2 & 441.3 & 547.2 & 184.3 & 233.3 \\
\hline Max.-Min. & 2337 & 2334 & 2334 & 670 & 556 \\
\hline CV & 2.47 & 1.42 & 1.11 & 0.6 & 0.6 \\
\hline
\end{tabular}

Table 9. TG geotechnical property statistics broken down by UP

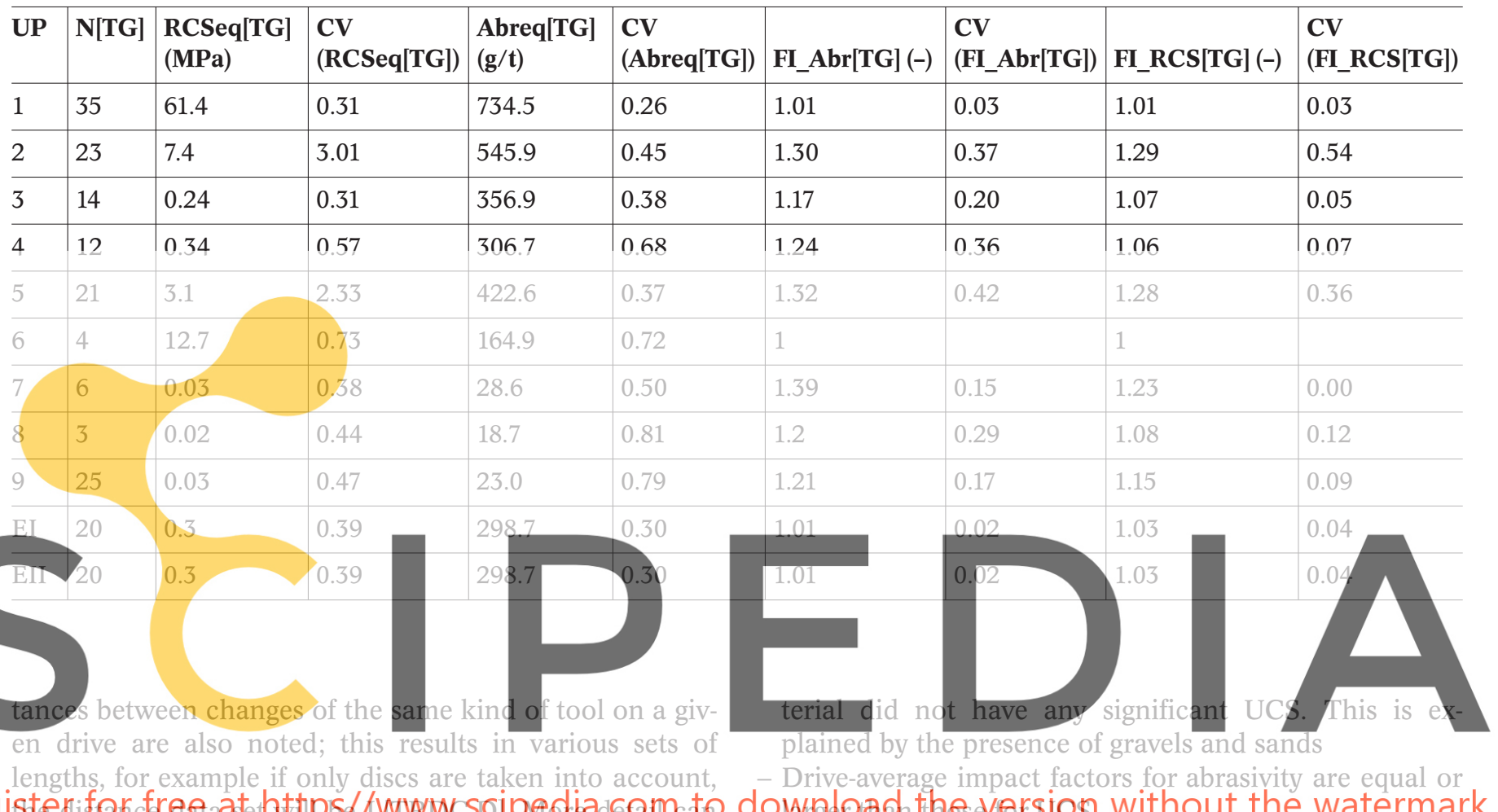

be found in [1]. Sometimes it is also useful to note the aggregated number of replacements per drive: the notation then is $\mathrm{N}_{\mathrm{H}}[\mathrm{UP}]$.

On the drives of L9 project 201, drive maintenance stretches were determined. Table 7 shows the main statistics of this population. The aggregate averaged value $\left(\overline{\mathrm{L}}_{\mathrm{H}}\right)[\mathrm{TRDC}]$ is $126 \mathrm{~m}$. The statistics of maintenance stretch length L[TRDC-X], when restricted to a particular tool category, are presented in Table 8. On average, scraper changes were more distant than those of picks, which were again more distant than those affecting discs.

\section{Results and discussion}

\subsection{Geotechnical properties on geotechnical stretches}

Table 9 shows the statistics of $T G$ geotechnical properties for each drive (UP). Mean values of each property at each drive are presented in Fig. 5. Based in this results it is apparent that

- The RCSeq[TG] cover more than three orders of magnitude. Rocks were found in UPs1, 5 and 6.

- Mean Abreq[TG] values for UPs cover a complete range of LCPC scale (from "not abrasive" to "very abrasive").

- Mean RCSeq[TG] and mean Abreq[TG] are poorly correlated in general: some drives were abrasive but the ma-

\subsection{Tool changes in drive maintenance stretches (TRDC)}

8,596 tool changes were recorded during 215 stoppages. Sometimes all tools were changed, sometimes only one. Picks were replaced more often since they are present in higher numbers on the wheels. Total tools changed per drive $\left(\mathrm{N}_{\mathrm{H}}[\mathrm{UP}]\right)$ are presented in Table 10 . Average number of tool changes per stoppage on each drive $\left(\overline{\mathrm{N}}_{\mathrm{H}}\right.$ [TRDC]) are presented in Table 11. Some observations are pertinent here:

- On drive UP1 (where there were only discs), each change included few tools, and many stoppages took place. This machine operated mostly in open mode [2] on a drive dominated by soft rock.

- On UP2, rock was infrequent but there were abundant river gravels, which seem to have been particularly damaging for picks. Gravels were also present in drives UP3, 4 and 5.

- UP4 and UP5 were almost parallel drives. They had stiff clay and gravels and, in UP5, some decomposed granite. On paper, the second drive looked more difficult and the maintenance programme was more carefully planned. The machine was also more carefully driven: the net advance rate was $15 \%$ slower on UP5. However 

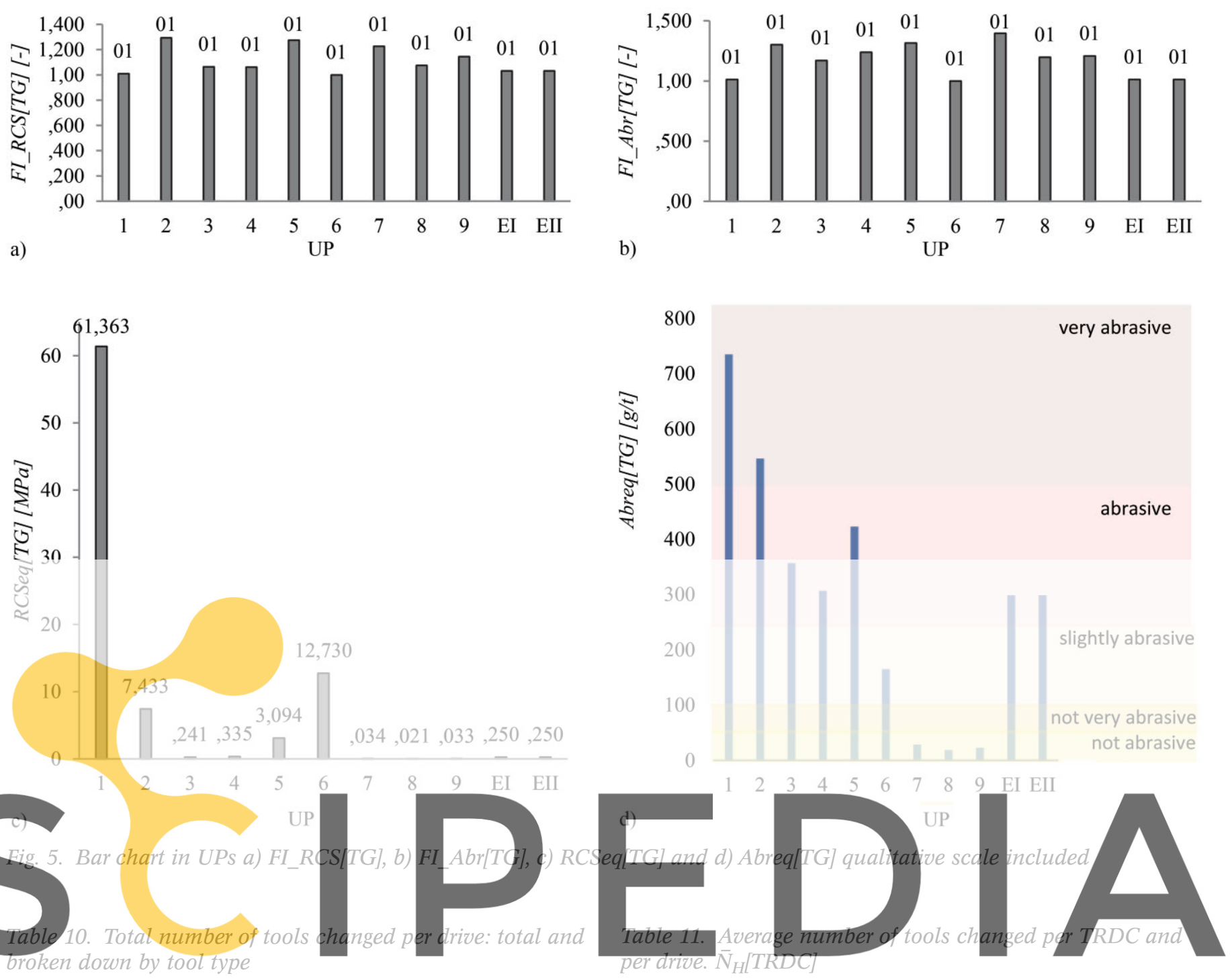

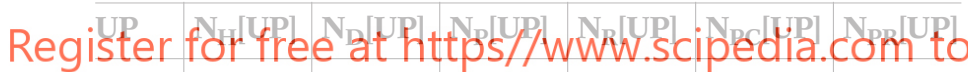

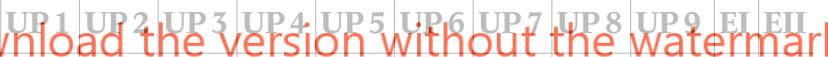

\begin{tabular}{l|l|l|l|l|l|l}
\hline 2 & 1640 & 1640 & & & & \\
\hline 3 & 530 & 73 & 318 & 139 & & \\
\hline 4 & 1540 & 249 & 1130 & 161 & & \\
\hline 5 & 596 & 168 & 410 & 18 & & \\
\hline 6 & 285 & 92 & 193 & 0 & & \\
\hline 7 & 279 & 35 & 197 & 47 & & \\
\hline 8 & 246 & 23 & 182 & 41 & & \\
\hline 9 & 519 & 43 & 396 & 80 & & \\
\hline EI & 443 & & & & 226 & 217 \\
\hline EII & 222 & & & & 116 & 106 \\
\hline Total & 8596 & 2591 & 4787 & 553 & 342 & 323
\end{tabular}

the gross advance rate (including all maintenance stoppages) ended being $75 \%$ faster for UP5 than for UP4 [6].

- The Terrassa drives EI and EII had very similar geological profiles and the machines were twins. The differences between them show the importance of a learning curve in machine operation.

\begin{tabular}{l|l|l|l|l|l|l|l|l|l|l|l}
$\mathrm{D}$ & 13 & 38 & 24 & 31 & 15 & 7 & 7 & 8 & 14 & & \\
\hline $\mathrm{P}$ & - & 163 & 106 & 81 & 37 & 19 & 39 & 46 & 66 & & \\
\hline $\mathrm{R}$ & - & 8 & 46 & 16 & 9 & - & 12 & 14 & 16 & & \\
\hline $\mathrm{PC}$ & & & & & & & & & & 32 & 17 \\
\hline $\mathrm{PR}$ & & & & & & & & & & 54 & 15 \\
\hline
\end{tabular}

\subsection{Normalized tool consumption and abrasivity}

Geotechnical properties could also be assigned to TRDC stretches, taking into account their intersection with different TG. This enables looking for correlations between geotechnical properties and tool consumption measures. For instance, normalized tool consumption was defined for each TRDC stretch as:

$\mathrm{CRH}=\frac{\mathrm{L}[\mathrm{TRDC}]}{\mathrm{N}_{\mathrm{H}[\mathrm{TRDC}]} / \mathrm{N}_{\mathrm{H} 0} 100}$

where $\mathrm{N}_{\mathrm{H} 0}$ is the number of tool positions on the cutter head. Fig. 6 shows that $C R H$ decreases as abrasiveness increases. 


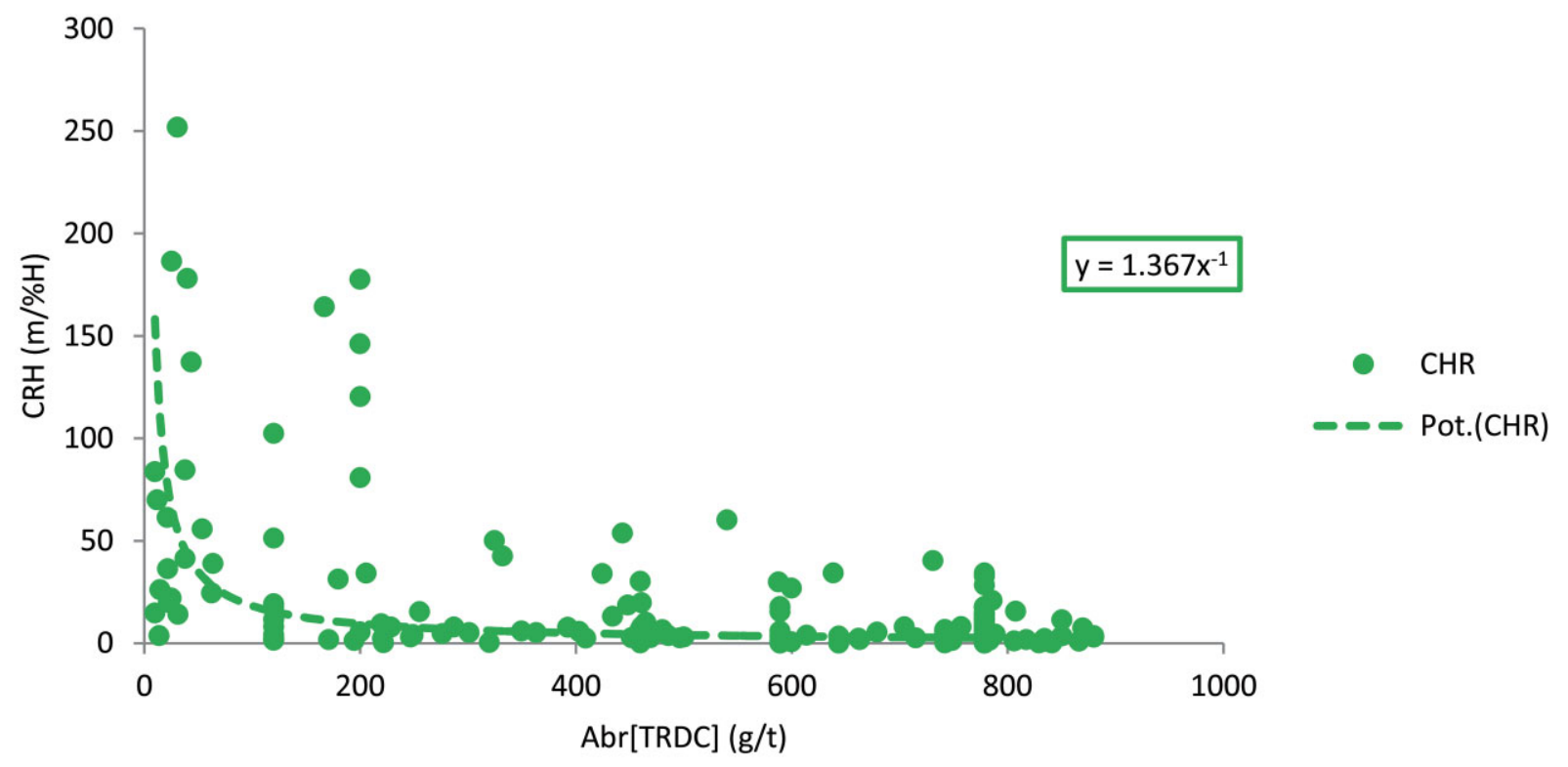

Fig. 6. CRH against Abreq[TRDC]

\section{Conclusions}

In this report, the database of tunnel drive records was analyzed from the geotechnical and maintenance points of view. An effort was made to quantify geotechnical heterogeneity using Impact Factors to quantify variability within
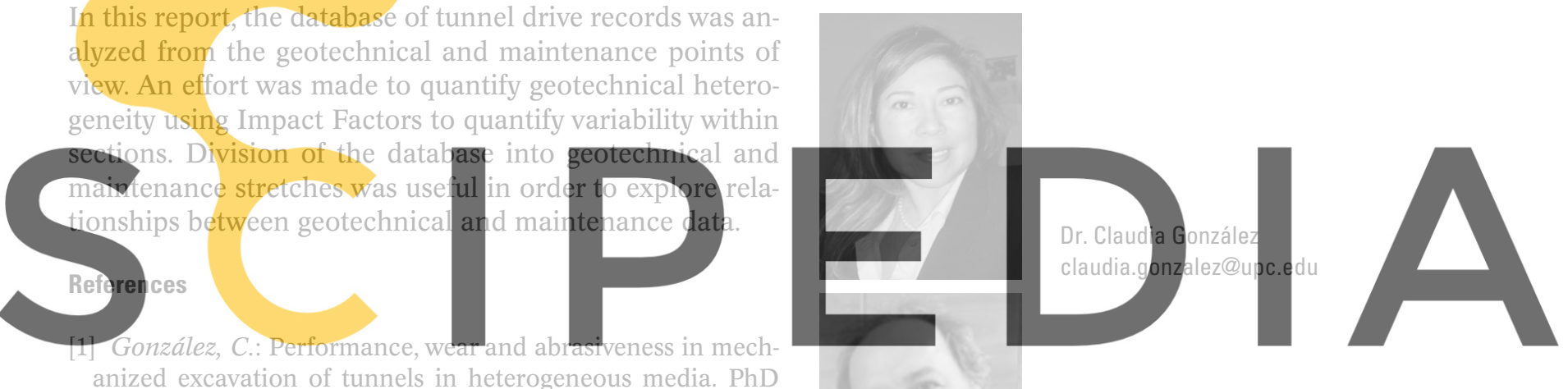

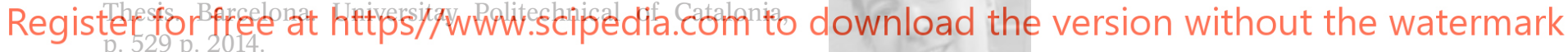

[2] González, C., Arroyo, M., Gens, A.: Abrasivity measures on geotechnical materials of the Barcelona area. Eurock2014. Vigo, Spain. 2014.

[3] Lovat Inc.: 2000. TBM Design Metro Seville Line 1: Solutions to Difficult Conditions. [Online] Available at: http:// www.lovat.com/pdfs_powerpoints/Articles-\&-Papers.

[4] González, C., Arroyo, M., Gens, A.: 2013. Abrasiveness and its influence on the performance in continuous driving. Obras y Proyectos 13, UCSC, Concepción, Chile. ISSN 07182805.

[5] Thuro, K., Singer, J., Käsling, H., Bauer, M.: Soil Abrasivity Assessment Using the LCPC Testing Device. Felsbau 24 (2006), pp. 37-45.

[6] González, C., Arroyo, M., Gens, A.: Production, performance and maintenance time observations in mixed soil-rock EPB drives. Panamerican conference on soil mechanics and geotechnical engineering. Buenos Aires. Argentine. 2015.

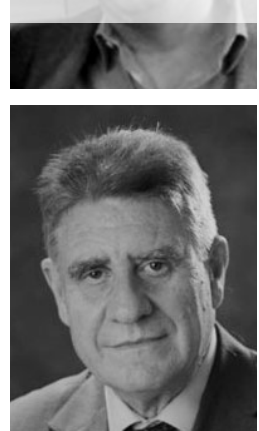

Ass. Prof. Marcos Arroyo marcos.arroyo@upc.edu

Prof. Antonio Gens antonio.gens@upc.edu

Departamento de Ingeniería del Terreno Cartográfica y Geofísica Universidad Politécnica de Cataluña Campus Diagonal Nord,

Edificio D2.C, Jordi Girona, 1-3, 08034 Barcelona, Spain 